\title{
An evaluation of operating room throughput in a stand-alone soft-tissue trauma operating theatre
}

\author{
Brian D O’Donnell ${ }^{1}$, Ken Walsh ${ }^{1}$, Aileen Murphy², Brendan McElroy ${ }^{2}$, Gabriella Iohom¹, George D Shorten ${ }^{1}$
}

${ }^{1}$ Department of Anaesthesia, Cork University Hospital, and University College Cork, Ireland

${ }^{2}$ Department of Economics, University College Cork, Cork, Ireland

\begin{abstract}
Background. Operating room time is a limited, expensive commodity in acute hospitals. Strategies aimed at reduction of non-operative time improve operating room throughput and capacity. We conducted a prospective study to evaluate and augment operating room throughput and capacity using context-specific work practice changes.

Methods. Following institutional and ethical approval, an interdisciplinary group designed and introduced a series of work practice changes specific to a stand-alone soft tissue trauma theatre, comprising modifications to patient processing, staff behaviours and additional anaesthesiologist hours. Time intervals relating to each patient were measured during a 16 week period before and after implementing work practice changes. The primary outcome measure was non-operative time, with daily caseload and cancellations amongst secondary outcome measures.

Results. 251 procedures were included over 58 working days ( 8 to 17 Monday to Friday). Nonoperative time [55.6 (31.1) vs 52.3 (9.8) minutes, $p=0.48$ ], daily caseload [4 [1-9] vs 4 [2-7], $p=0.56$ ], and the number of daily cancellations [3 [0-11] vs $5[0-8], \mathrm{p}=0.38]$, did not differ between baseline and study phases. Regional anaesthesia for upper limb surgery increased during the study phase [26/59 $(44.0 \%)$ vs $10 / 63(15.9 \%), p=0.014]$ with resultant decrease in mean duration of recovery room stay [20.7 (17.7) vs 30 (20.5) minutes, $\mathrm{p}=0.0001]$ and increased recovery room bypass [26/116 $(22.4 \%)$ vs $6 / 135(4.4 \%), \mathrm{p}=$ $0.0002]$. Avoidable delays accounted for 124.8 (72.2) minutes of theatre time lost each day.

Conclusion. In conclusion, additional attending anaesthesiologist hours combined with work practice changes did not impact on measures of theatre throughput and capacity. The study identified important variables that contribute to avoidable delays, and points the way for future research.
\end{abstract}

Keywords: operating theatre, soft-tissue trauma, parallel processing, anaesthesia, case duration

\section{Introduction}

Optimizing operating room (OR) use is a key tenet of good management in acute hospitals. Operating room time has an estimated hourly cost of $€ 560$ during a normal working day at our institution. In the acute hospital setting, OR time is a limited commodity on which variable demands are placed in an unpredictable fashion. Strategies which optimize the proportion of

\begin{tabular}{ll}
\hline Address for correspondence: & Dr. Brian D O’Donnell \\
& Department of Anaesthesia \\
& Cork University Hospital \\
& Wilton Road, Cork, Ireland \\
& E-mail: briodnl@gmail.com
\end{tabular}

OR time used for surgery, have been shown to improve OR efficiency and throughput [1-4]. Effective use of OR resources enables timely patient care and maximizes efficiency during the perioperative period.

Patient care in the OR can occur sequentially (one patient's OR journey is completed before another begins) or in parallel (multiple tasks can be performed for more than one patient within the OR environs simultaneously). Patients are routinely processed sequentially at our institution. Using sequential processing in a single OR environment (one room for anaesthesia induction, surgery and anaesthesia emergence), theatre turnover time must be decreased by $50 \%$ of the total surgical time to permit one additional case to be undertaken per standard working day [1]. Parallel 
processing involves the use of physical space and additional staff outside the OR to induce anaesthesia (general and/or regional anaesthesia), allowing two patients to be managed simultaneously by the same anaesthesiology team. Parallel processing decreases OR non-operative time and facilitates additional cases during the normal working day [2].

Deliberate system design of both the OR physical environment and of OR work practices to incorporate parallel processing can contribute to improved efficiency and throughput [3]. The use of regional anaesthesia in a system utilising parallel processing procedures has been shown to further improve efficiency and OR throughput [5]. Ultimately, modifications to work practice may decrease non-operative time, the proportion of time during which the OR is used for patient care other than surgery, thereby increasing OR capacity.

We conducted a prospective 'before and after' study to evaluate measures of operating room throughput. The objective of this prospective study was to increase the operating room throughput by one additional surgical case per standard working day (defined as 9 hours) by introducing specific work practice changes, and thereby decreasing non-operative time.

\section{Methods}

The Cork Teaching Hospitals Research Ethics Committee and the Executive Management Board of Cork University Hospital granted approval for this study. The project received financial support from the Health Services National Partnership Forum (www.hsnpf.ie) and from BBraun Medical (Ireland) Limited. The study was conducted in partnership with the Department of Economics (Division of Healthcare Economics) at University College Cork, Ireland.

The primary outcome measure for this study was non-operative time. Non-operative time is defined as the time that the operating room is used for purposes other than surgery [6]. It is the interval from the time of completion of surgery and dressings in "Patient $X$ ", to the time surgery commences in "Patient $\mathrm{X}+1$ ". This interval comprises anaesthesia emergence and transfer of Patient X to the recovery room, OR clean-up, next case set-up, and induction of anaesthesia in "Patient $\mathrm{X}+1$ ". It was postulated that a decrease in non-operative time would increase utilization of the OR for surgery, thus resulting in an increase of daily surgical activity by one case per day.

\section{Setting}

The study was conducted in a dedicated soft-tissue trauma surgical unit at a busy 800 bed tertiary referral university teaching hospital. Both adults and children are treated in this unit. The OR serves patients who have suffered soft-tissue injury such as extremity lacerations with tendon and nerve injury, burns, traumatic skin loss and decubitous ulcers. The Division of Plastic Surgery at Cork University Hospital provides surgical services for these patients. Patients with facial injuries such as zygoma and mandibular fractures are also treated in this OR with combined plastic surgery/ maxillofacial surgery input.

The soft-tissue surgical unit is remote from the main block of operating theatres. The unit comprises a reception area, changing areas, staff rest room, administrative office, OR, recovery room (accommodating one patient at a time), minor procedure room, and storage rooms (Figure 1). The OR operates from 8 am to $5 \mathrm{pm}$ Monday to Friday.

\section{Baseline Phase}

The objective of this phase of the study was to collect quantitative and qualitative time data pertaining to the patient journey through the operating theatre complex. Having secured ethical and institutional approval, a baseline study phase began. During this eight-week phase, no modifications were made to patient care or patient processing through the OR. By convention, patients underwent sequential processing in the OR. Data relating to time intervals in the patient journey through the operating theatre complex were collected by a nominated anaesthesia resident. The times measured were those defined by the 'Association of Anaesthesia Clinical Directors' Procedural Times Glossary' [6] (Table 1). Delays in patient management were recorded. The duration and cause of each delay were noted. The data obtained formed the basis for the creation of a context-specific OR management plan.

\section{Interdisciplinary Group}

A consultation group was assembled comprising Surgeons, Anaesthesiologists, OR Nurses, OR Porters (Orderlies), Divisional Business Managers, Hospital Nurse Managers and Clerical Officers. The objective of this interdisciplinary group was to facilitate the implementation of OR work practice changes for the study phase of the study. Before, during and after the baseline phase the interdisciplinary group working under the guidance and ethos of the Health Services National Partnership Forum devised an OR management plan. The objective of the plan was to facilitate one additional case per day. Increased capacity was to be achieved by decreasing non-operative time thereby, increasing the proportion of the working day in which the OR was available for surgery. This required a transition from sequential patient processing to parallel patient processing and the use of regional anaesthesia when 


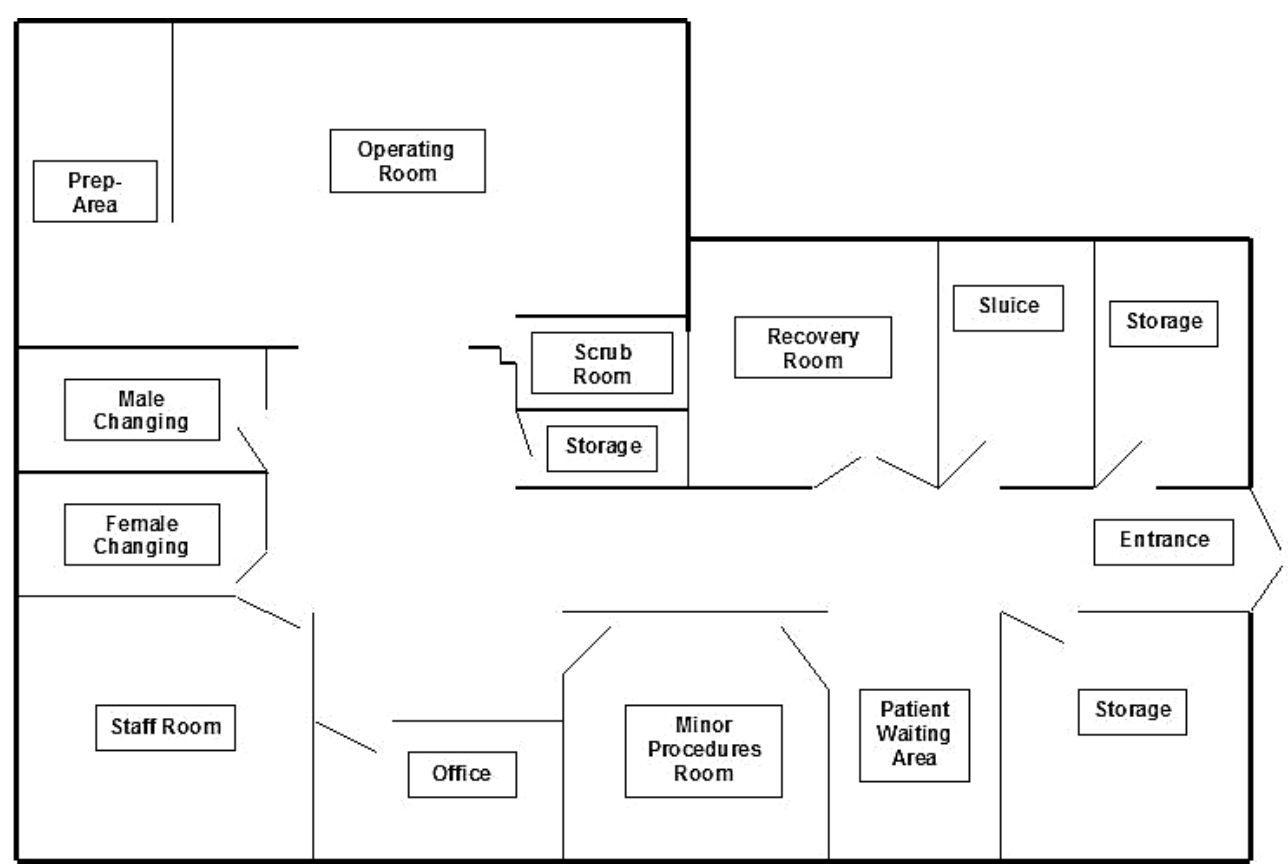

Fig. 1. Schematic representation of soft-tissue trauma operating theatre complex structure and layout (Outline not to scale)

Table 1. Study data collection sheet for each patient's OR journey.

Association of Anaesthesia Clinical Directors' (AACD) time points and definitions are included.

\begin{tabular}{|c|c|c|c|}
\hline Time point & Definition & $\begin{array}{l}\text { Time } 24 \mathrm{hr} \\
\text { clock }\end{array}$ & $\begin{array}{l}\text { Record of } \\
\text { delay }\end{array}$ \\
\hline Room Set-up Start (RSS) & Time when personnel begin setting up in the OR for the first/next case & & \\
\hline Room Ready (RR) & $\begin{array}{l}\text { Time when OR is cleaned and supplies and equipment necessary for the } \\
\text { beginning of the next case are present }\end{array}$ & & \\
\hline $\begin{array}{l}\text { Procedure Physician Available } \\
\text { (PPA) }\end{array}$ & Time surgeon available to perform planned surgery & & \\
\hline $\begin{array}{l}\text { Anaesthesiologist of record In } \\
\text { (AA) }\end{array}$ & Time anaesthesiologist available to perform anaesthesia & & \\
\hline Patient Sent-for (PS) & $\begin{array}{l}\text { Time when transporting service (nurse \& porter) is notified to deliver } \\
\text { patient to the OR }\end{array}$ & & \\
\hline Patient Available (PA) & Time the patient arrives in the theatre reception & & \\
\hline Anaesthesia Start (AS) & $\begin{array}{l}\text { Time when a member of the anaesthesia team begins preparing the } \\
\text { patient for anaesthetic (monitors, IV access etc.) }\end{array}$ & & \\
\hline Anaesthesia Induction (AI) & $\begin{array}{l}\text { Time at which anaesthesiologist begins the administration of } \\
\text { anaesthesia agents or regional anaesthetic block }\end{array}$ & & \\
\hline Anaesthesia Ready (AR) & $\begin{array}{l}\text { Time at which patient has sufficient level of anaesthesia to commence } \\
\text { surgery }\end{array}$ & & \\
\hline Preparation Start Time (PS) & Time where patient positioning and skin preparation begins & & \\
\hline Procedure Start Time (PST) & The time a procedure is begun (skin incision) & & \\
\hline Procedure Finish (PF) & $\begin{array}{l}\text { Time at which instrument and sponge count complete, all dressings etc. } \\
\text { secured, all procedure related activities complete }\end{array}$ & & \\
\hline Anaesthesia Finish (AF) & Time patient ready for discharge to PACU & & \\
\hline Patient Out of Room (POR) & Time at which patient leaves the OR for PACU & & \\
\hline $\begin{array}{l}\text { Room Clean-up Start (RCS) } \\
\text { (RSS for next patient) }\end{array}$ & Time housekeeping begins cleanup & & \\
\hline $\begin{array}{l}\text { Room Clean-up Finish (RCF) } \\
\text { (RR for next patient) }\end{array}$ & $\begin{array}{l}\text { Time OR is clean and ready, set-up with supplies and equipment for the } \\
\text { next case }\end{array}$ & & \\
\hline Arrival in PACU (APACU) & Time of arrival in PACU/recovery room & & \\
\hline $\begin{array}{l}\text { Ready For Discharge from PACU } \\
\text { (RDPACU) }\end{array}$ & Time the patient meets discharge criteria from PACU & & \\
\hline Discharge from PACU (DPACU) & Time the patient actually leaves the PACU & & \\
\hline Arrival back on ward (ABW) & Time the patient arrives back on the ward & & \\
\hline
\end{tabular}


feasible. The plan included specific elements incorporating work practice modification, the temporary deployment of additional staff numbers, and modification of work-related staff behaviours (Table 2). The interdisciplinary group discussed the implications of the introduction of significant work practice changes, barriers were identified and an implementation strategy agreed. A transition period of five days was allowed between baseline and implementation phases to facilitate familiarization of staff with the bundle of work practice changes. Due to a national embargo on additional staff recruitment by the Health Services Executive (HSE), it was not possible to recruit additional nursing staff for the study period. data-recording sheet (Table 1). Delays were quantified as to the amount of operating time lost. The performance of a minor case under local anaesthetic in the main operating theatre (given the presence of a minor procedures area - Figure 1) was considered a delay.

Data Analysis

Only complete datasheets were entered for analysis. Data were analyzed using Epilnfo ${ }^{\mathrm{TM}} 2002$ (Centers for Disease Control and Prevention, USA) statistics software. Normally distributed continuous data were analyzed using the unpaired Student $t$ test for samples of unequal variance or a one sided ANOVA as appropriate. Non-normally distributed data were

Table 2. Summary of planned work practice changes

\begin{tabular}{|c|c|c|}
\hline Variable & Baseline phase & Study phase \\
\hline \multirow[t]{3}{*}{ Staff numbers } & 5 nursing staff per day & $\begin{array}{l}\text { Planned increase of one additional nurse per day not permitted due to } \\
\text { Health Services Executive directive on Whole-time Equivalents and cost } \\
\text { containment } 2008\end{array}$ \\
\hline & & $\begin{array}{l}\text { Attending Anaesthesiologist all day } \\
\text { (Attending anaesthesiologist with specialist training in peripheral nerve } \\
\text { block) }\end{array}$ \\
\hline & Resident Anaesthesiologist all day & Resident Anaesthesiologist all day \\
\hline \multirow{4}{*}{$\begin{array}{l}\text { Operating room } \\
\text { practice }\end{array}$} & First patient to arrive in the OR by convention & First patient to arrive in the OR by $08: 20$ \\
\hline & Serial patient processing & $\begin{array}{l}\text { Parallel processing of patients; transforming and utilising the recovery } \\
\text { room as an anaesthesia induction/block room } \\
\text { (limited by inability to provide additional nursing staff) }\end{array}$ \\
\hline & $\begin{array}{l}\text { All patients brought to OR by porter in } \\
\text { wheelchair/OR trolley }\end{array}$ & Ambulatory patients to walk to the $\mathrm{OR}$ \\
\hline & Routine recovery following anaesthesia & $\begin{array}{l}\text { Protocolised recovery using Modified Aldrete Score (Appendix). } \\
\text { Recovery room bypass facilitated where appropriate. }\end{array}$ \\
\hline \multirow[t]{9}{*}{ Staff behaviours } & \multirow[t]{2}{*}{ Improved communication } & Between OR Nurses and Wards \\
\hline & & Between Anaesthesiology and Surgery \\
\hline & \multirow[t]{4}{*}{ Punctuality } & Nursing available by $08: 00$ with OR set-up by $08: 20$ \\
\hline & & Anaesthesiology available by $08: 00$ for anaesthesia start by $08: 20$ \\
\hline & & Surgeon available to start procedure by $08: 20$ \\
\hline & & Patient available and in OR by $08: 20$ \\
\hline & \multirow[t]{3}{*}{ Patient processing } & $\begin{array}{l}\text { All appropriate pre-op assessment and care planning to be conducted prior } \\
\text { to patient arrival in OR (except in emergency) }\end{array}$ \\
\hline & & Patient notes to be complete and present \\
\hline & & $\begin{array}{l}\text { Patient consent and pre-operative investigations complete and present in } \\
\text { patient chart }\end{array}$ \\
\hline
\end{tabular}

\section{Study Phase}

Following implementation of the OR management plan, an eight-week study phase began. Data were again collected relating to time intervals in the patient journey through the operating theatre complex by a nominated anaesthesia resident. The extent to which the OR management plan was implemented was overseen by members of the interdisciplinary group.

\section{Evaluation of Delays}

Factors, which were deemed to obstruct the running of the OR from 08:00 to 17:00, were recorded on the analyzed using the non-parametric Mann-Whitney/ Wilcoxon two-sample test. Differences in proportions were compared by the Yates Chi-square test. Statistical significance was considered at $p<0.05$. It was the intention of the collaborative group to perform a cost minimization analysis of the measures introduced. A cost-minimization analysis was planned in collaboration with the Department of Economics (Division of Healthcare Economics) at University College Cork should the project deliver a reduction in non-operative time and increased OR capacity. 


\section{Results}

Data were collected over two eight-week periods from February $11^{\text {th }} 2008$ to April $2^{\text {nd }} 2008$ and from April $7^{\text {th }} 2008$ to June $3^{\text {rd }} 2008$. These two periods consisted of 71 standard working days (35 days baseline phase; 36 day study phase). Nine days were lost to data collection for logistical reasons (4 baseline phase; 5 study phase). Four datasheets were filled incompletely during the study phase and not suitable for entry in subsequent analysis. Data relating to 58 working days (31 days baseline phase; 27 day study phase) representing 251 patient journeys through the OR were collected. Baseline patient demographics, including anaesthesia modality and type of surgery are shown in Table 3.

The primary outcome measure was non-operative time. Non-operative time did not differ between baseline and study phases [55.6 (31.1) vs 52.3 (9.8) minutes respectively, $p=0.48]$. The number of cases performed each day [4 [1-9] vs 4 [2-7], $p=0.56]$, and the number of cancellations per day $[3[0-11]$ vs $5[0-$ $8], p=0.38$ ], were similar in the baseline and study phases respectively. Summary data pertaining to the working day are presented in Table 4.
A significantly greater proportion of patients underwent peripheral nerve block in the study phase compared to the baseline phase [28/116 (24.1\%) vs $10 / 135(7.4 \%), p=0.0003]$. In particular, the proportion of upper limb cases in adults performed using peripheral nerve block increased in the study phase [26/59 $(44.0 \%)$ vs $10 / 63(15.9 \%), p=0.014]$. Patient parallel processing occurred more frequently during the study phase compared to the baseline phase [6/116 (5.2\%) vs $0 / 135(0.0 \%), p=0.01]$. Significantly more patients received general anaesthesia in the baseline phase compared to the study phase [123/135 (91.1\%) vs $87 /$ $116(75.0 \%), p=0.001]$.

Recovery room bypass was achieved more frequently during the study phase than during the baseline phase [26/116 (22.4\%) vs 6/135 (4.4\%), p= $0.0002]$. There was a decrease in mean recovery room stay during the study phase compared to the baseline phase [20.7 (17.7) vs 30 (20.5), p = 0.0001].

The quantity and duration of recorded daily delays were similar in both phases. One hundred and thirty seven delays were recorded during the study period (69 in the baseline phase; 68 in the study phase) Combining data from both phases of the study, delays accounted for 124.8 (72.2) minutes of theatre time lost.

Table 3. Baseline data

\begin{tabular}{|c|c|c|c|c|}
\hline \multicolumn{2}{|c|}{$\begin{array}{l}\text { Summary of patient data } \\
\mathrm{n}=251\end{array}$} & $\begin{array}{l}\text { Baseline phase } \\
(\mathrm{n}=135)\end{array}$ & $\begin{array}{l}\text { Study phase } \\
(\mathrm{n}=116)\end{array}$ & Significance \\
\hline \multicolumn{2}{|l|}{ Age (years) } & $26.4(19.5)$ & $28.6(22.9)$ & $\mathrm{P}=0.23^{\#}$ \\
\hline \multicolumn{2}{|l|}{ Gender } & $\mathrm{M}: \mathrm{F}=90: 45$ & $\mathrm{M}: \mathrm{F}=86: 30$ & $\mathrm{P}=0.22^{+}$ \\
\hline $\mathrm{ASA}^{1}$ grade & $\begin{array}{l}\text { ASA } 1 \\
\text { ASA } 2 \\
\text { ASA } 3\end{array}$ & $\begin{array}{l}103 \\
27 \\
5\end{array}$ & $\begin{array}{l}85 \\
20 \\
11\end{array}$ & $\mathrm{P}=0.16^{+}$ \\
\hline \multirow[t]{3}{*}{ Anaesthesia } & General anaesthesia & 123 & 87 & $\mathrm{P}=0.0013^{+}$ \\
\hline & Peripheral nerve block & 10 & 28 & $\mathrm{P}=0.0003^{+}$ \\
\hline & Intrathecal anaesthesia & 2 & 1 & $\mathrm{P}=1^{+}$ \\
\hline \multirow[t]{5}{*}{ Type of surgery } & Upper limb trauma & 63 & 59 & $\mathrm{P}=0.52^{+}$ \\
\hline & Facial trauma & 42 & 22 & $\mathrm{P}=0.03^{+}$ \\
\hline & Burns surgery & 6 & 11 & $\mathrm{P}=0.13^{+}$ \\
\hline & Wound-care & 21 & 20 & $\mathrm{P}=0.73^{+}$ \\
\hline & Other & 3 & 4 & $\mathrm{P}=0.70^{+}$ \\
\hline \multicolumn{2}{|c|}{$\begin{array}{l}\text { Summary of daily data } \\
\mathrm{N}=58 \text { days }\end{array}$} & $(n=31)$ & $(\mathrm{n}=27)$ & \\
\hline \multicolumn{2}{|c|}{ Duration of working day (min) } & $552.5(73.4)$ & $540.5(58.2)$ & $\mathrm{P}=0.49^{*}$ \\
\hline \multicolumn{2}{|c|}{ Nursing staff allocation per day (n) } & $4.8(0.6)$ & $4.6(0.7)$ & $\mathrm{P}=0.44$ \\
\hline \multicolumn{2}{|c|}{ Individual surgery duration (min) } & $51.6(47.9)$ & $51.8(39.6)$ & $\mathrm{P}=0.9^{\mathrm{x}}$ \\
\hline \multicolumn{2}{|c|}{ Individual anaesthesia duration (min) } & $73(52.1)$ & $80.1(62.2)$ & $\mathrm{p}=0.34^{\mathrm{x}}$ \\
\hline \multicolumn{2}{|c|}{$\begin{array}{l}\text { Total daily surgery time }(\mathrm{min}) \\
\text { [Individual surgery duration } \times \text { number of surgeries per day] }\end{array}$} & $224.5(74.6)$ & $220.5(65.4)$ & $\mathrm{P}=0.8^{*}$ \\
\hline \multicolumn{2}{|c|}{$\begin{array}{l}\% \text { Working day performing surgery } \\
{[\text { Total daily surgery time/length of working day } \times 100]}\end{array}$} & $39.6(11.3)$ & $41.1(11.4)$ & $\mathrm{P}=0.61^{*}$ \\
\hline \multicolumn{2}{|c|}{$\begin{array}{l}\text { Total daily anaesthesia time }(\mathrm{min}) \\
\text { [Individual anaesthesia duration } \times \text { number of anaesthetics per day] }\end{array}$} & $317.9(81.4)$ & $341.1(83.5)$ & $\mathrm{P}=0.29^{*}$ \\
\hline \multicolumn{2}{|c|}{$\begin{array}{l}\% \text { Working day performing anaesthesia } \\
{[\text { Total daily anaesthesia time/length of working day } \times 100]}\end{array}$} & $56.2(12.2)$ & $62.9(12.9)$ & $\mathrm{P}=0.04^{*}$ \\
\hline
\end{tabular}

Data represented as mean (standard deviation); ${ }^{1} \mathrm{ASA}=$ American Society of Anesthesiologists; + = Yates Chi-square test, 2-tailed; * = ANOVA; \# = Mann-Whitney/Wilcoxon two-sample test; $\mathrm{x}=$ unpaired Student $\mathrm{t}$-test for samples of unequal variance 
Table 4. Delays of greater than 30 minutes

\begin{tabular}{lcc}
\hline Reason for delay & $\begin{array}{c}\text { Number of } \\
\text { occurrences }(\mathrm{n}=104)\end{array}$ & $\begin{array}{c}\text { Mean (SD) duration of delay } \\
(\mathrm{min})\end{array}$ \\
\hline Case performed under local/infiltration anaesthesia in main OR & 22 & $73.3(31.9)$ \\
Insufficient nursing staff to maintain patient flow through OR & 21 & $40(13.2)$ \\
Delay discharging patient from OR to ward due to ward nurse unavailability & 20 & $42.6(13.7)$ \\
Surgeon delayed & 10 & $67(22.3)$ \\
Anaesthesiologist delayed & 9 & $33.3(9.4)$ \\
Phase 1\& 2 recovery in OR & 7 & $65.7(38.8)$ \\
Patient scheduling & 5 & $61.7(58.1)$ \\
Other & 10 & $35.4(17.5)$ \\
\hline
\end{tabular}

One hundred and four delays of greater than 30 minutes duration were recorded during the sixteen-week study period (Table 4). The use of the OR for minor procedures not requiring the presence of an anaesthesiologist, and factors relating to nursing staff numbers engaged in perioperative patient care, were listed most frequently as causes of delays. Thirty three delays of less than 30 minutes were recorded over the study period.

As the study failed to show any difference in primary or secondary outcome measures, a cost minimization analysis was not performed.

\section{Discussion}

Despite satisfactory implementation of a management plan aimed at increasing OR throughput, nonoperative time was not decreased, operating room capacity was not increased and the resultant goal of one additional case per day was not achieved. Nonoperative time for both phases of the study exceeded 50 minutes. This can be interpreted as 50 minutes of surgical inactivity in the OR between cases. Nonoperative time consists of phase 1 recovery and transfer of patient $\mathrm{X}$ from the OR to the recovery room, cleaning the OR, set-up of instruments for the next case, and providing anaesthesia for patient $\mathrm{X}+1$. Interestingly, the average duration of individual surgeries was 51 minutes in both groups (Table 3). Combining long non-operative times and measured avoidable delays, it is unsurprising that, on average, only $40 \%$ of the working day of this OR is spent performing surgery. Therefore, $60 \%$ of OR time is spent on tasks essential to patient care other than surgery. Non-operative time may be significantly reduced by providing anaesthesia for patient $\mathrm{X}+1$ outside of the OR [7].

Parallel processing was not possible during the study period. Parallel processing requires increased staffing levels and a specific clinical area appropriate for the provision of anaesthesia outside the operating room. The physical space for parallel processing existed and was appropriately equipped prior to this study. The presence of attending anaesthesiologists increased from baseline to study phases from $50-100 \%$ of the working week. This increase in the number of anaesthesiologists alone, did not impact positively on service provision. The safe implementation of parallel processing requires additional staff to support the anaesthesiologist in providing care for two patients simultaneously.

Avoidable delays to the operating list were common during this study. One hundred and thirty seven avoidable delays were recorded during the 58-day study period. On average two hours of operating room time were lost per day due to avoidable delays. The impact of this phenomenon is case cancellations. On average four cases were cancelled per day over the combined baseline and study phases. These patients required accommodation within the inpatient hospital system while awaiting surgery, thereby incurring significant cost and occupying scarce inpatient bed space. Many of these cancelled cases are accommodated during out-of-hours operating lists at the weekends at considerable extra cost to the institution. Elimination of avoidable delays by identification and remedy of causes through deliberate system design and interdisciplinary cooperation, may allow improved OR efficiency and a reduction in case cancellations [8].

The proportion of patients undergoing regional anaesthesia alone for upper limb surgery increased during the study phase from $15.9 \%$ to $44.0 \%$. Only $10 \%$ were parallel processed as per protocol. There was no appreciable impact on non-operative time. Despite this, the use of regional anaesthesia for extremity surgery, combined with a protocolized recovery room process facilitated a decrease in the duration of recovery room stay and recovery room utilisation. The potential to shorten duration of recovery room stay and bypass the phase 2 recovery by using regional anaesthesia has been previously reported worldwide along with other benefits [9-11]. Our own group demonstrated in a separate study that all upper limb trauma patients undergoing surgery under brachial plexus block alone bypassed the recovery room [12]. This has the potential to allow redeployment of nursing 
within the OR as part of an integrated OR management plan. Unfortunately the full advantages of parallel processing, regional anaesthesia and recovery room bypass were not realized during the study phase. It is nonetheless encouraging that limited introduction of the planned study interventions had a positive impact on reducing the mean duration of recovery room stay.

Our overall results are in stark contrast with those of a surgeon-led model to improve operating theatre change-over time and overall efficiency. The impact of a single surgeon team-based work practice model translated into $58 \%$ reduction in median change-over time and no cancellations due to lack of time in the intervention group compared with 37 cancellations in the control group [13].

Our study has a number of important weaknesses. Data were lost during both the baseline and study phases. Although this represented a small quantity of data, it is unknown whether the study outcome may have been altered by the inclusion of lost data. During the study phase planned changes in work practice, such as parallel processing, were not frequently achieved. It is therefore possibly not surprising that there was no difference in primary outcome measures between baseline and study phases. Finally, we were unable to perform a meaningful economic analysis of the study as there were no differences in primary or secondary outcomes. Doubling the hours provided by an attending anaesthesiologist added significant costs without achieving desired targets.

In conclusion, additional attending anaesthesiologist hours combined with work practice changes did not impact on non-operative time. Improvements were seen in secondary outcome measures such as the duration of recovery room stay and the ability to bypass the recovery room. To achieve improvement in the primary outcome measure additional nursing/physician support staff is required. The study identified important variables that contribute to avoidable delays, and points the way for future research into realizing improved efficiency measures in a stand-alone OR providing soft-tissue trauma surgery.

\section{Conflict of interest}

Nothing to declare

\section{Funding}

This investigation was funded in part by:

1. A project grant from the Health Services National Partnership Forum (Ireland);

2. BBraun Ireland Ltd.

\section{References}

1. Dexter F, Coffin S, Tinker JH. Decreases in anesthesia-controlled time cannot permit one additional surgical operation to be reliably scheduled during the workday. Anesth Analg 1995; 81: 1263-1268

2. Torkki PM, Marjamaa RA, Torkki MI, Kallio PE, Kirvelä OA. Use of anesthesia induction rooms can increase the number of urgent orthopedic cases completed within 7 hours. Anesthesiology 2005; 103: 401-405. DOI: 10.1097/00000542200508000-00024

3. Sandberg WS, Daily B, Egan M, Stahl JE, Goldman JM, Wiklund RA, et al. Deliberate perioperative systems design improves operating room throughput. Anesthesiology 2005; 103: 406418

4. Cendán JC, Good M. interdisciplinary work flow assessment and redesign decreases operating room turnover time and allows for additional caseload. Arch Surg 2006; 141: 65-69. DOI: 10.1001/ archsurg. 141.1.65

5. Smith MP, Sandberg WS, Foss J, Massoli K, Kanda M, Barsoum $\mathrm{W}$, et al. High-throughput operating room system for joint arthroplasties durably outperforms routine processes. Anesthesiology 2008; 109: 25-35. DOI: 10.1097/ ALN.0b013e31817881c7

6. Donham RT, Mazzei WJ, Jones RL. Association of Anesthesia Clinical Directors' Procedural Times Glossary: Glossary of times used for scheduling and monitoring of diagnostic and therapeutic procedures. Am J Anesthesiol 1996; 23(5S): 3-12

7. Hanss R, Buttgereit B, Tonner PH, Bein B, Schleppers A, Steinfath $\mathrm{M}$, et al. Overlapping induction of anesthesia: an analysis of benefits and costs. Anesthesiology 2005; 103: 391-400. DOI: 10.1097/00000542-200508000-00023

8. Harders M, Malangoni MA, Weight S, Sidhu T. Improving operating room efficiency through process redesign. Surgery 2006; 140: 509-516. DOI: 10.1016/j.surg.2006.06.018

9. Hadzic A, Williams BA, Karaca PE, Hobeika P, Unis G, Dermksian J, et al. For outpatient rotator cuff surgery, nerve block anesthesia provides superior same-day recovery over general anesthesia. Anesthesiology 2005; 102: 1001-1007

10. McCartney CJ, Brull R, Chan VW, Katz J, Abbas S, Graham B, et al. Early but no long-term benefit of regional compared with general anesthesia for ambulatory hand surgery. Anesthesiology 2004; 101: 461-467. DOI: 10.1097/01.sa.0000165212. 75986.64

11. McIsaac DI, Cole ET, McCartney CJ. Impact of including regional anaesthesia in enhanced recovery protocols: a scoping review. Br J Anaesth 2015; 115 Suppl 2: ii46-56. DOI: 10.1093/bja/ aev376

12. O'Donnell BD, Ryan H, O'Sullivan O, Iohom G. Ultrasoundguided axillary brachial plexus block with 20 milliliters local anesthetic mixture versus general anesthesia for upper limb trauma surgery: an observer-blinded, prospective, randomized, controlled trial. Anesth Analg 2009; 109: 279-283. DOI: 10.1213/ ane.0b013e3181a3e721

13. Mizumoto R, Cristaudo AT, Hendahewa R. A surgeon-led model to improve operating theatre change-over time and overall efficiency: A randomised controlled trial. Int J Surg 2016; 30: 83-89. DOI: $10.1016 /$ j.ijsu.2016.04.033 


\section{Appendix}

\section{Level of consciousness Score}

Awake and oriented Arousable with minimal stimulation 1 Responsive to tactile stimulation

\section{Hemodynamic stability}

$\mathrm{BP}<15 \%$ initial MAP

BP $15 \%-30 \%$ initial MAP $\mathrm{BP}>30 \%$ below initial MAP

\section{Oxygen saturation status}

Maintains value $>90 \%$ on room air $\quad 2$ Requires supplemental $35-40 \% \mathrm{O}_{2} \quad 1$ Saturation $<90 \%$ with $35-40 \% \mathrm{O}_{2} \quad 0$

\section{Postoperative emetic symptoms}

None or mild nausea

Transient vomiting or retching

Moderate/severe nausea/vomiting

Total score 14

Fast-track Score

Fast-track Ready

\section{Physical activity}

2

Move all extremities

2

(except block limb)

Some weakness of extremities 1

Unable to move extremities

\section{Respiratory stability}

2 Able to breathe deeply

1 Tachypnoea with good cough

0 Dyspnoeic with weak cough

\section{Postoperative pain assessment}

None or mild discomfort 2

Moderate to severe pain $\quad 1$

Persistent severe pain
2

1

0 